\title{
Towards a register-based census in Oman
}

\author{
Ali Hussain Al-Lawati \\ Ministry of Technology and Communications \\ Muscat, Oman \\ ali.allawati@mtc.gov.om
}

\author{
Luís Soares Barbosa \\ United Nations University (UNU-EGOV) \\ Guimarães, Portugal \\ barbosa@unu.edu
}

\begin{abstract}
A national census is an official count of a country's population that aims to motivate and measure sustainable development. Traditionally, a census is a cumbersome manual operation that involves distributing surveys to all households in the country through field agents or by mail. Recently, some countries have utilized voluntary electronic submissions in addition to the manual work to reduce costs and increase efficiency. However, an increasing number of countries are resorting to a register-based census that uses pre-existing official registers to derive its data. This paper describes Oman's upcoming register-based census, eCensus 2020, and analyses it against the European Commission's necessary conditions that facilitate a successful transition from a traditional to a register-based census [1].
\end{abstract}

\section{CCS CONCEPTS}

- Applied computing $\rightarrow$ Computers in other domains $\rightarrow$ Computing in government $\rightarrow$ E-government

\section{KEYWORDS}

e-Census 2020, register-based census, Oman census, population and housing census, e-Census

\section{ACM Reference format:}

Ali Hussain Al-Lawati, Luís Soares Barbosa. 2020. Towards a registerbased census in Oman. In Proceedings of the $13^{\text {th }}$ International Conference on Theory and Practice of Electronic Governance (ICEGOV 2020), 23-25 September 2020, Athens, Greece, 4 pages. https://doi.org/10.1145/3428502.3428631

\section{INTRODUCTION}

Since the 1950s, the UN Statistics Division has advocated member countries to conduct a population and housing census on a decennial basis [2]. Many countries, having recognized the value of the data collected in influencing policy-making, funds allocation, and sustainable development have performed this

Publication rights licensed to ACM ACM acknowledges that this contribution was authored or co-authored by an employee, contractor or affiliate of a national government. As such, the Government retains a nonexclusive, royalty-free right to publish or reproduce this article, or to allow others to do so, for Government purposes only.

ICEGOV'20, September 23-25, 2020, Athens, Greece

(C) 2020 Copyright is held by the owner/author(s). Publication rights licensed to ACM ACM ISBN 978-1-4503-7674-7/20/09...\$15.00

https://doi.org/10.1145/3428502.3428631 activity. In Oman, the first census was conducted in 1993 and subsequently in both 2003 and 2010 [3].

While traditionally a census involved field workers visiting households to conduct interviews or drop questionnaires, the advent and ubiquity of access to online government services has facilitated the usage of online channels to collect a percentage of the surveys. Such an approach usually involves heads of households volunteering the census questionnaire online rather than filling the paper version, thereby reducing the burden on the government body in conducting the count, as well as the overall cost of the census [4].

Popularized by Denmark [5], some countries have begun conducting a census based on their official registers. This approach takes advantage of data registers maintained and updated by various government entities, and cross-referencing them where necessary to obtain the relevant data required for the census. For example, a population register may be crossreferenced against a workforce register to compute the wage discrepancies between age groups and across provinces in the country.

This paper intends to describe and analyse challenges, and expectations, in order to contribute to a body of lessons learnt on the impact of digitalization on census programs. The objectives of this paper are:

- Introduce the e-Census 2020 system, and some of its key objectives.

- Analyse the level of preparedness of the country to move to a register-based system.

- Put forward a number of recommendations for its ongoing implementation.

Section 2 outlines the methodology used for this study. In section 3 , we briefly describe the main purposes of a census and how they are better served by a register-based or a combined census. Section 4 describes the Oman e-Census 2020 project and section 5 puts the project to a test against a set of necessary conditions for a successful transition documented in the literature. Finally, section 6 summarizes with conclusions and recommendations. 
For simplicity, we use the following abbreviations in this paper:

- E-Census 2020 - Oman's register-based census program in for 2020.

- NCSI - The National Centre for Statistics and Information, which is the government body responsible for conducting the census

- E-Tranformation: The e-government transformation project in Oman, described in subsection 4.2.

\section{METHODOLOGY}

This research is based on an objective assessment of the e-Census initiative in Oman, in the spirit, but not full compliance, of actionbased research principles. Actually, the first author was involved with the e-Census 2020 project during a period of 3 months between May 2019 and August 2019 as a technical advisor. This association was limited to the integration options, capabilities, and best practices. During this activity he conducted an analysis of the potential of the success of the e-Census 2020 project in Oman, we evaluate the system against the necessary conditions proposed by the Economic Commission for Europe [1], as follows: i) legal base; ii) public approval; iii) stakeholder approval; iv) cooperation between the NSI and other authorities; v) comprehensive and reliable statistical register system; vi) unified identification system; vii) knowledge of administrative sources; and viii) transparency.

The research was framed on a systematic literature review through Google Scholar with the keywords "register-based census" and "e-census". Sample cases were drawn from the literature on which the reader may establish similarities and distinction from the effort reported for Oman.

Finally, it is relevant to mention that at the time of writing this paper, neither of the authors are affiliated or involved with the National Center of Statistical Information (NCSI) Oman in any manner.

\section{LITERATURE REVIEW}

The census plays an essential role in projecting population growth, area growths, and establishing the "national statistical systems" [4] that guide government planning. For example, the house of commons treasury committee identified the main purposes of a census as [6]: i) Allocation of resources to local authorities, such as the police; ii) definition of ratios at a national and local level to guide policy-making; iii) Local planning.

The traditional census is an enumeration of households using paper questionnaires that also collect information on other characteristics, and can be filled-in by the head of household or by a field agent [2]. Because of the high investment and requirements of implementing a census, some countries, such as Germany, have for many decades not received the public support necessary to carry through [7]. Further, as a result of the fast moving pace of development, the traditional census no longer provides a timely measure of information [6]. The results of a census often become available a few years after the data collection process starts [5]. As a result, some find that the traditional census provides outdated results, and thereby fails to serve its purpose.

As a way to control its cost, the traditional census has been recently augmented with internet-based versions of the questionnaire. This combined approach relies on existing data registers from official records or previous census to invite heads of households to fill the application online. In 2011, two thirds of the responses to the census came online [8]. Canada and Portugal saw internet responses at $55 \%$ and $50 \%$, respectively, of the total responses collected [8]. Germany implemented a combined census in 2010 - census is based on some register data complemented by collection of information directly from the population through paper or online channels. In the United States, the 2020 census uses administrative data to prefill mail-out forms.

Denmark and several other European countries have conducted their census based on administrative registers for decades. While, the process of creating and maintaining high quality registers is expensive, the benefits of such an approach are significant [2]. Aside from the potential of creating a census on need basis, and on a timelier basis, the cost savings are substantial. For example, in 2010 the cost of the Danish census per person was $\$ 0.03$, while the cost per person in the United States was $\$ 48.9$ [7].

\section{THE OMAN E-CENSUS PROJECT}

\subsection{Introduction}

The census 2020 program (e-Census 2020) was formed through the issuance of a royal decree in 2015 mandating the National Center of Statistical Information (NCSI) in Oman to perform a national census in 2020, allocating the budget, and assigning the project an independent status to exempt it from restrictions and spending controls in place on government projects [9]. The royal decree specified the census should be electronic and also stated the year on which the census should be complete in compliance with the UN 2020 World Population and Hosing Census Programme, which recommends a census to be conducted every 10 years.

The government of Oman represented by the NCSI kicked off the e-Census 2020 in 2017 as a completely register-based census based on 5-phases [10]:

1) Preparation: establishing the methodologies and operational strategies

2) Data Readiness:

3) Establishment of the e-Census System

4) Pilot

5) Go-live

This is an ongoing project, phases 3 is still in-progress and phases 4 and 5 have not started as of the writing of this paper.

A key goal of the e-Census 2020 project is to implement population, housing, and establishment hubs that update in realtime when any change is triggered in the source register.

\subsection{Background}

The e-Census 2020 project relies on two key national initiatives:

4.2.1. eGovernment Transformation 
In 2012, the cabinet of ministers assigned the Information Technology Authority (ITA) with the implementation of an eGovernment Transformation Plan that consists of 4 phases [11]:

1) Government Information and Data

2) Government Services

3) Government eTransactions

4) Indicators and Measurement

The first phase included a mandate that government entities perform data cleansing and eliminate data duplication and redundancy in its registers. In addition, the government entity shall provide access to its data to other government entities and shall rely on the information owning entity through electronic integration.

The second phase mandated the creation of a service catalog and business process re-engineering, while the third phase appointed committees in every government entity to review the implementation of the plan. Finally, the fourth phase measured the progress of each entity on an annual basis with respect to the stated goals.

\subsubsection{Integration Platform}

The e-Oman Integration Platform is a data hub that facilitates data exchange in real-time between different government agencies. It currently hosts more than 12 data providers and 35 data consumers. It enables the exchange of current data across government while avoiding the burden of data duplication and respecting the country guidelines of data ownership.

The exchange of data within the Integration Platform happens in a response to a transaction occurring at a government entity that requires additional information from a second one. For example, the National Registry System (NRS) provides population data to the Ministry of education when an individual enrolls in a University or the Ministry of Commerce in the event an individual registers a business.

\section{RESEARCH FINDINGS}

\subsection{Introduction}

While many factors may affect the success of e-Census 2020, from an outsider's perspective we evaluate it against what the Economic Commission for Europe calls the necessary conditions conditions that need to be in place for a country that wants to move from a traditional census to a register-based census. Oman is embarking on a register-based census for the first time, and in the next several subsections, we evaluate each of the criteria and consider the difficulties that may arise.

\subsection{Compliance with necessary conditions}

\subsubsection{Legal Base}

NCSI was given full legal authority through the issuance of a royal decree which is a law issued by the head of state that comes into immediate effect [12]. The project was assigned an independent financial and legal status and given a mandate to access the information it requires [9].

\subsubsection{Public approval}

Community awareness of the project, its benefits and the savings in terms of time and budget, as well as the simplifications of eservices is done using nationwide campaigns on TV, radio, newspapers, and the social media. The campaigns encourage citizens to update their information [10].

\subsubsection{Stakeholder approval and cooperation between the NSI and other authorities}

To ensure the approval and cooperation of all stakeholders, the royal decree created a supreme national committee for the census that included the heads of all the authorities and ministries that maintain the required registers. The eTranformation project created technical committees in each entity and provided external oversight and management of the progress and an indicator of where each entity stands. This helped tremendously in the eCensus 2020 project's assessment of readiness and risk control.

\subsubsection{Comprehensive and reliable statistical register system}

Key requirements of a register-based census are high-quality government registers, and the ability to cross-reference them in a secure manner while meeting privacy concerns. A statistical register system requires the administrative registers to be up to date and access to various registers securely.

While the eTranformation project mentioned previously helped bring many government entities to a level of readiness, there remained some entities which lagged in this effort. One such key entity that was still using paper-based systems was the Ministry of Justice. In Oman, this ministry is the custodian of marriage and divorce certificates and as such the owner of such data.

As part of e-Census 2020 and through the combined effort of the eTransformation project and the support of e-Census 2020, an electronic system named Tawtheeq was created. The migration of the paper-based history of the Ministry to an electronic register was a key achievement driven by the requirements of e-Census 2020.

In order to facilitate the propagation of different data registers into the e-Census 2020 platform, the Integration Platform was a de-facto choice given it has been serving in this role for many years. The Integration platform was already connected to over 20 government entities. This helped expedite the connectivity of these entities to e-Census 2020.

When considering the statistical system, a key difficulty that may arises is differences in concepts and definitions of the social indicators of the census [5]. In other words, indicators in a traditional census in some cases may not be derived from data in administrative registers. Examples of this include illegal residents, literacy rate, and primary residence. However, it is important to note that moving to a register-based census requires some change of definitions. For example, some statistics such as the population in a given area changes from "a de facto to a de jure definition" [5].

\subsubsection{Unified identification system}

Some countries such as India and Turkey built their population registers from previous census, while others such as Norway and 
Sweden, combine the data from the various districts in the country to construct a population register.

In Oman, the civil register which was established in 1993 contains a comprehensive list of citizens and residents uniquely identified and forms the basis of the ID card. Registration is mandatory and an identification system is assigned to a new born on the birth certificate. One objective of the civil register is to include the main civil events of birth, marriage, divorce, and death. It was developed as a demographic database to support database statistics [13].

The civil register is analogous to the CPR register in Denmark which, as in Denmark, is used by all major public administrative systems [5]. As in Denmark, Oman has not needed to invent an identification system to implement a register-based census.

\subsubsection{Knowledge of administrative sources}

While the eTranformation system has helped establish the administrative sources of many authorities, a key challenge that remains is the lack of a sufficient addressing system. Most citizens and businesses are associated with postal office box addresses. As such, establishing a primary place of residence remains a challenge and local indicators may see a higher level of discrepancy in e-Census 2020.

However, the Oman national spatial data infrastructure initiative that will provide a unified addressing system is currently underway. It is intended to establish a database of addresses linking geo coordinates with the citizen, business, rental contract, and other registers [14]. While the system was intended to support the e-Census 2020 project, it may take some time until full adoption takes place and addressing becomes a component of the population and business database.

\subsubsection{Transparency}

While the project is inclusive of all stakeholder authorities in the supreme and technical committees in addition to an information committee consisting of radio, television, and news agencies, we were not able to gather futher information for research purposes through an online request and a formal request delivered to NCSI.

\subsection{Summary}

The e-Census 2020 satisfies a majority of the necessary conditions for moving to a register-based census. It is not clear how the census will change due to the absence of an address register. Further, transparency on the project is lacking, whether on its progress or on scope, issues encountered, and decisions made.

\section{CONCLUSIONS \& FUTURE WORK}

The move from traditional census to a register-based census was a gradual process in many countries [8]. These countries utilized combined methods in route to a full register-based census. Other countries, such as Denmark, skipped the business census on their first attempt at implementing a register-based census [5].

Oman satisfies a majority, but not all, of the necessary conditions to implementing a register-based census. As such, it remains to be seen whether alternative methods such as statistical approximations [15] will be used to derive local indicators, or whether they will be omitted in the 2020 census report. However, the methodology of the census system being build will support a census on-demand based on the data hubs that will be built into the census system.

The capability of the census system to serve as the go to register for administrative information is a key measure of its accuracy, and success. As such, perhaps NCSI should consider serving as the sole source of government information in the near future.

\section{ACKNOWLEDGEMENTS}

This paper is a result of the project "SmartEGOV: Harnessing EGOV for Smart Governance (Foundations, methods, Tools) / NORTE-01-0145-FEDER-000037", supported by Norte Portugal Regional Operational Programme (NORTE 2020), under the PORTUGAL 2020 Partnership Agreement, through the European Regional Development Fund (EFDR).

\section{REFERENCES}

[1] UN. ECE: Guidelines on the use of registers and administrative data for population and housing censuses., Economic Commission for Europe, Geneva (2018)

[2] Valente, P.: Census taking in Europe: how are populations counted in 2010 ? Population \& Societies(467), 1 (2010)

[3] Hassan, A. M.: Selected Data and Indicators From the Results of General Populations, Housing and Establishments Censuses (2010 -2003-1993).

[4] Baffour, B., King, T., Valente, P.: The modern census: evolution, examples and evaluation. International Statistical Review 81(3), 407-425 (2013)

[5] Borchsenius, L.: From a Conventional to a Register-based Census of Population. Les Recensements après (2001) Denmark's experience.

[6] Harper, G., Mayhew, L.: Applications of population counts based on administrative data at local level. Applied Spatial Analysis and Policy 5(3), 183-209 (2012)

[7] Coleman, D.: The twilight of the census. PoPulation and develoPment review 38, 334-351 (2013)

[8] Valente, P.: From the 2010 to the 2020 census round in the UNECE region Plans by countries on census methodology and technology., Economic Commission for Europe, Geneva (2015)

[9] To conduct an electronic census of population, housings and establishments. (2015)

[10] National Centre for Statistics and Information: E-Census 2020. (Accessed 2019)

[11] Information Technology Authority: eGovernment Transformation Policies.

[12] Royal Decrees. (Accessed 2018) Available at: https://omanportal.gov.om/wps/portal/index/gov/omangov/RoyalDecrees/

[13] Royal Oman Police, D. o. P. R.: Civil Status System. (Accessed 2017) Available at: https://www.rop.gov.om/english/cs_system.html

[14] National spatial data infrastructure: Oman National Spatial Data Infrastructure Enabling GeoSmart Oman. (2017)

[15] Lenk, M.: Methods of register based census in Austria. Vienna: Statistik Austria (2008) 